\title{
Physical and Psychological Problems of the Elderly at an Aged Care Center
}

\author{
Gyawali $\mathrm{M}^{1 *}$, Khan $\mathrm{A}^{2}$, Chaudhury $\mathrm{R}^{3}$, Khadka $\mathrm{R}^{4}$
}

${ }^{1}$ National Academic for Medical Science (NAMS), Nepal; ${ }^{2}$ AK Healthcare Trust (AKKHT) Green Road, Dhanmondi Dhaka, Bangladesh; ${ }^{3}$ Department of Social Relations, East West University, Dhaka, Bangladesh; ${ }^{4}$ Department of Surgery, International Education College, Jiangxi University of TCM, Nanchang, China

\begin{abstract}
Introduction: As the world is aging, there is a growing interest in various morbidity patterns among the elderly population. This study aims to find out the physical and psychological problems among elderly people and to determine the factors associated with the problems.

Methods: A cross-sectional descriptive study was carried out among 46 elderly people who were residents at the Aged Care Center in Dhaka, Bangladesh. Elderly aged 60-years and above were selected purposefully for the study. Physical disability, geriatric depression, cognitive impairment was assessed using the Barthel index, Geriatric depression scale, Elderly Cognitive Assessment Questionnaire respectively. The association between sociodemographic data and physical disability, depression and cognitive impairment were also evaluated by using bivariate analysis.

Results: The mean age of the respondents was $73.3 \pm 7.41$ years and among them $52 \%$ were females. Among the participants, the prevalence of physical disabilities was $17.39 \%$ and the commonest problem was climbing the stairs. The Prevalence of cognitive impairment was $13.04 \%$ and the commonest impairment was found in memory recall. The Prevalence of geriatric depression was $32.6 \%$. The prevalence of depression and cognitive impairment were higher among unmarried, illiterate and unemployed respondents. Overall physical and psychological impairment was higher in the age group 80 to 89 years and also in females.
\end{abstract}

Conclusion: Increasing age, particularly those who belonged to age group 80-89 years were at significant risk for physical disability, depression and cognitive impairment.

Keywords: Elderly people; Physical health problem; Psychological health problem

\section{INTRODUCTION}

Aging is an inevitable process of life. In this $21^{\text {st }}$ century, with the advancement in medical science and technology, reducing mortality rate, increasing life expectancies and declining fertility rate there is an increment in the trend of population aging [1]. Aging presents both challenges and opportunities. The World Health Organization has therefore taken the slogan "Ageing and Health" on the world health day 2012 to address this phenomenon in a way that is affordable and sustainable for families and society [2].

By 2025 the elderly population globally is expected to rise more than 1.2 billion, with close to $75 \%$ of it in developing countries, thus making population aging a great challenge [3]. Earlier the aging process was restricted to developed countries is now the place of population aging is much faster and rapid in developing countries compared to developed countries [4]. Significantly, the most rapid increases in the 65 and older population are occurring in developing countries, which will see a jump of 140 percent by 2030 [5]. In a study, it shows that in Bangladesh the elderly population will be increased from about 8 million in 2001 to 44 million in 2050 [6]. We are aging not just as individuals or communities, but as a world. As the trend of aging is expected to be more rapid in developing nations because of this; developing nations will have very little time than the developed nations to adapt to the consequences of the aging population [7]. The elderly, in general, face various challenges that are associated with physical and psychological changes commonly associated with the aging process. The main challenges for older people are noncommunicable diseases. Urinary tract infection is a very common problem, but it is more prominent in elderly patients and its average prevalence is $25-40 \%$ [8].

Correspondence to: Gyawali M, Associate Professor, National Academic for Medical Science (NAMS), Nepal, Tel: +91-11-26588718; E-mail: meegyawali@gmail.com

Received: May 25, 2019, Accepted: March 05, 2019, Published: March 12, 2019

Citation: Gyawali M, Khan A, Chaudhury R, Khadka R (2020) Physical and Psychological Problems of the Elderly at Aged Care Center. J Gerontol Geriatr Res 9: 509. doi: 10.35248/2167-0374.20.9.509

Copyright: (C) 2020 Gyawali M, et al. This is an open-access article distributed under the terms of the Creative Commons Attribution License, which permits unrestricted use, distribution, and reproduction in any medium, provided the original author and source are credited. 
Functional status can be influenced by biological or physiological impairment and socioeconomic factors. Functional ability is a key indicator of the elderly to stay at home. Functional status has been used to describe a motor function, ability to perform Activities of Daily Living (ADL) [9]. Mental health problems are also common in old age and they remain undetected and untreated. Mental health problems in the elderly are the result of a complex interaction of social, psychological and biological factors [10]. Morbidity among elderly people has an important influence on their physical functioning and psychological well-being. Many elderlies have several disorders at the same time and the incidence of diseases increases with age [11]. Depression and depressive symptoms are common in older people. Often depression is difficult to recognize. Sometimes slowing of activity, fear or lack of pleasure or lack of interest in work is thought to be due to normal aging [12]. Depression is likely to increase in number due to an increase in life expectancy, rapidly changing social and physical environment that gives rise to psychological stress, increase in morbidity due to chronic non-communicable disease [13]. Elderly people with untreated depression are more likely to have worse outcomes from conditions like hypertension, diabetes mellitus, and heart disease. Memory is strongly related to the ability to perform tasks of daily living and in turn, to live independently. Elderly Cognitive Assessment Questionnaire (ECAQ) was used to determine whether the respondents were cognitively impaired. ECAQ is a ten-item screening test assessing long term memory, orientation, and recall status. Cognitive function is "an intellectual process by which one becomes aware of, perceives or comprehends ideas. It involves all aspects of perception, thinking, reasoning and remembering" [14]. Aging is associated with differential patterns of decline in cognitive function. The trend of this decline varies from person to person and depends on demographic factors, lifestyle, and in particular, health-related factors [15]. Cognitive impairment is a common problem among the elderly. It was estimated that 25 million people had dementia in 2005 and the number is expected to double every 20 years [16]. The aim of this study is to find out the physical and psychological problems among elderly people and to determine the factors associated with the problems.

\section{MATERIALS AND METHODS}

The study was conducted in Aged Care Centre Agargoun, Dhaka Bangladesh. A cross-sectional study was carried out to find the physical and psychological problems over a period of 9 months, from the month of April 2017 to December 2017. Study tool and procedures: Convenience sampling method was applied in the study where all the participants who were living in the aged care center were included and those who were not willing to take part in the study were excluded. The informed consent form was signed by the interviewee after being informed about the study purpose by the researcher. The formal permission was obtained from the aged care authority for conducting the study. Both open-ended and close-ended questionnaire was used during the study. The Barthel Index of activities of daily living, Geriatric Depression Scale (GDS) and Elderly Cognitive Assessment Questionnaire (ECAQ) was used as the study instruments to measure the physical and psychological disabilities of the elderly people. Barthel Index of activities of daily living: Physical disability was determined by ten-item from the Barthel Index questionnaire. The ten ADL items assessed were feeding, bathing, dressing, grooming, toileting, bladder control, bowel control and transfer from bed to chair, walking and stair climbing. For this study, physical disability was defined as needing help in one or more of these ADL activities.

The sum of the patient's scores for each item is made. Total score ranges from less than 20 for a maximum of 100 where patient scoring between:

- 80 and 100 are regarded as independent,

- 60-79 needing minimal help in their ADL,

- 40-59 are considered as a partial dependent,

- 20-39 are considered as very dependent and

- $\quad<20$ are considered as totally dependent.

\section{Geriatric Depression Scale (GDS)}

The data was collected in a predesigned, structured proforma. For assessment of depression, Geriatric Depression Scale-15 (GDS-15) questions were administered after explaining the purpose of study. Of the 15 items, 10 indicated the presence of depression when answered positively, while the rest (question numbers 1, 5, 7, 11, 13) indicated depression when answered negatively. The patient scoring between:

- 0-4: are considered normal

- 5-8: are considered as mild depression

- 9-11: are considered as moderate depression

- 12-15: are considered as severe depression

\section{Elderly Cognitive Assessment Questionnaire (ECAQ)}

This was used to screen cognitive impairment status among the elderly respondents. The ECAQ consists of 10 items grouped into 3 categories: memory ( 3 items), orientation ( 6 items) and memory recall (1 item). Each item has a weighting of one mark for correct response and 0 for an incorrect answer. Respondents score of:

- 6 or more is indicative of normal memory and

- 5 and below indicates cognitive impairment.

Data were as analyzed using computer-based statistical software. Results were analyzed by the researcher's t-test. A 'p' value of $<0.05$ was considered statistically significant. After compilation, the data were presented in the form of tables, figures, and graphs, as necessary.

\section{RESULTS}

A total of 46 respondents took part in the study.

\section{Socio-demographic factors}

The majority of the respondents 17 (37\%) are from the age group $70-79$ years. The mean age of the respondents was $73.3 \pm 7.41$ years with a median of 74 years. Among 46 residents, only one of them is currently engaged in some social work whereas regarding past occupation, $20(43.5 \%)$ of them used to work at some private organizations and $5(10.9 \%)$ were engaged in government jobs. Out of 46 respondents 41 (89.9\%) are ever married, of which 24 
$(52.2 \%)$ are widowed, $15.2 \%$ are divorced and $21.7 \%$ are separated. Only $10.9 \%$ were reported to be single. Regarding educational status $25(54.34 \%)$ of them have completed secondary and higherlevel education. Data also shows that out of 46 respondents, 19 $(41.3 \%)$ had three or more than three children. The majority of 35 (76.1\%) of the respondents reported having never used any type of tobacco in their life.

\section{Barthel index score}

The index result showed a large majority of respondents 32 (69.56\%) were having problems climbing the stairs and $26(56.52 \%)$ of them had a problem transferring to bed. In overall categories the majority of respondents 38 (82.6\%) were independent; they can perform their daily physical activities by themselves. Whereas only $5(10.9 \%)$ were in need of minimal help during their physical activities and 2 (4.3) were very dependent on others for their physical activities of daily living.

\section{Geriatric Depression Scale (GDS)}

Study shows 14 (30.4\%) of the respondents were not satisfied with their life whereas 28 (60.9\%) said they have dropped many of their activities and their interest these days. Whereas the majority of respondents $35(76.1 \%)$ said that they feel that their life is not empty and $30(65.2 \%)$ said they don't feel bored. Among total respondents, over two-thirds of them $(67.4 \%)$ were in a normal state, whereas a one-third of them $(32.6 \%)$ were suffering from depression. This was measured using a score of $0-5$ as within the normal range, while 6 or greater being a possible indicator of depression from the GDS scale [17].

\section{Cognitive assessment}

Study shows that about 9 out of ten respondents, $89.1 \%$ remembered the number that was given to them and even $97.8 \%$ of them were able to state their age correctly. In the same way, $29(63 \%)$ of the respondents were able to give the correct answer about their place of birth. Two by two a calculation shows that out of 46 respondents the absolute majority of them have normal cognitive function $40(87 \%)$ and only $6(13 \%)$ had impaired cognitive functions (Table 1).

\section{DISCUSSION}

\section{Socio demographic profile}

The majority of the respondents were in the age group 70-79. There are more females $(52.2 \%)$ than males (47.8\%) among the study population. A similar pattern of the gender distribution of the elderly population is also seen in other studies. The study conducted by Sidik et al., Khaw, Teo, and Rashid, and Carluccio da Silva et al., showed the majority of respondents were female. These findings could be due to the comparatively higher longevity

Table 1: Physical and psychological problems of elderly respondents $(n=46)$ in aged care center Dhaka.

\begin{tabular}{lccc}
\hline Problems & Present & Absent & Prevalence (\%) \\
\hline Functional Dependence & 8 & 38 & 17.39 \\
\hline Depression & 15 & 31 & 32.60 \\
\hline Cognitive Impairment & 6 & 40 & 13.04 \\
\hline
\end{tabular}

of life in females than. On the contrary, Donat Tuna et al., showed male predominance.

As the present study was done at the old age center all the respondents were currently single. Among them, $89.1 \%$ were ever married and among them, the majority was widowed (52\%). This finding was similar to the study findings by Sidik et. al, Donat Tuna et al. and Taj Uddin et al., in Bangladesh. Among the widowed respondents, the majorities were female, and the proportion of currently single older women was observed to be higher than that of single older males. The findings of this study corresponded to the findings of that of the study done by the Bangladesh Bureau of Statistics and the study done by Sidik, et al. First, the husband is usually older which increases the chances that they will die before their wife; secondly, in the social context of Bangladesh, the widowed men have higher remarriage rates than the widowed women [18].

The majority of respondents never consumed any type of tobacco in their life, whereas a minority of respondents $2(4.3 \%)$ smoked and chewed tobacco. Bishwajit et al., observed 58.3\%, 54.5\%, 42.8\% and $72.2 \%$ of non-smoker elderly in Bangladesh, India, Nepal, and Srilanka respectively. Nargis et al., observed that the prevalence of tobacco use in Bangladesh was less among the elderly, compared to an adult population.

\section{Barthel index of activities of daily living}

This study showed, out of a total of 46 respondents, $17.39 \%$ had some kind of dependence on Activities of Daily Living (ADL) assessed by the Barthel Index (BI). The prevalence of ADL disability in the study population was similar to the findings obtained by other studies carried out in developed countries such as by Chaudhary et al. in the USA and 20\% in Japan. Community-based study in Malaysia done by Sidik et. al reported similar findings where $15.7 \%$ of the respondents were dependent at least for one function of the ADL. Different community-based studies in India also showed similar results like $17.6 \%$ of ADL disability was observed by Gupta et al and $16.16 \%$ by Chakrabarty et al. (Table 2 ).

\section{Association between activities of daily living and socio- demographic factors}

In the present study, the prevalence of functional disability increased with age above 70 years and the finding was statistically significant. Similar to our study, many other studies related to disability among the elderly have confirmed that increasing age tends to be associated with increased risk of disability. However, age alone may be a poor index of physiological function that is associated with an increased prevalence of disease conditions. There are other important factors to ignore as a strong contributor to the occurrence of disability. Heikkinen noted three main underlying causes of disability-diseases, injuries, and processes of aging. The correlation between ADL and other socio-demographic factors were statistically insignificant.

However, this study found a greater prevalence of disability among females than males and a similar finding was noted by Dolai and Chakrabarty and Gupta et al. Other studies have reported conflicting findings; some found no gender differences in disability incidence, whereas others have noted a higher prevalence of disability among women. Higher dependency rates in the case of 
females may be due to longer life expectancy of females than their male counterparts and a lower rate of recovery among disabled older women.

In this study prevalence of disability was found higher among nonsmoker than smokers. This finding is not in tune with Heikkinen's who suggested tobacco consumption and smoking increase risk in functional status decline.

\section{Geriatric Depression Scale (GDS)}

The prevalence of depression among the elderly in this study was $32.60 \%$, where $6(13 \%)$ had severe depression and $12(26.1 \%)$ had mild depression. Similar findings were noted by Sundru and Goru, where $31.7 \%$ of respondents had depression. Bishwajit et al., observed a higher prevalence of depression viz, 47.7\%, 40.3\%, and $40.4 \%$ in Bangladesh, India, and Nepal respectively. Other studies in Bangladesh also showed a higher prevalence of depression in the elderly population like $45 \%$ by Wahlin et al., and $59 \%$ by Das et al.

\section{Associations between the geriatric depression and socio- demographic factors}

In this study, the prevalence of depression was found highest among respondents aged 80-89 years and the finding was statistically significant. A similar finding was noted in various other studies. The reason for the increase in the prevalence of depression in elderly may be due to increased economic and physical dependency, loss of spouse and friends, negligence by the family members, loss of self-esteem and chronic-degenerative or neurological illness.

In this study, the prevalence of depression was found higher in females compared to males and similar finding was noted by various other studies in Bangladesh and abroad. Several factors that might explain the higher prevalence of depression in female-like, death of a spouse, socio-cultural barriers, lack of participation in incomegenerating activities during their life span, family responsibility and physiological changes, mainly early onset of menopause or postmenopause.

In this study, the prevalence of depression was found to be higher among the elderly respondents who were unemployed, and a similar finding was noted by Sidik et. al., and Rashid, Azizah and Rohana in Malaysia. Employment enhances one's self-confidence, selfesteem and empowers people to have control over their future and makes an individual feel like a valuable member of the community.

In the present study, we found that single respondents have a higher prevalence of depression and a similar finding was reported by Giri et al., Swarnalatha N. Rashid, Azizah and Rohana. The reason for this may be single elderly people might experience more loneliness, poorer social support, lower self-confidence.

In the present study, the prevalence of depression was found to be more in people with no formal education than that informally educated respondents and various other authors noted similar findings i.e., depression is inversely proportional to the literacy status. The higher educational level seems to have a protective effect against depression, which accumulates throughout life. Perhaps such accumulated mental problems give higher resilience against strain or stresses, hence protecting against anxiety and depression is important (Table 3).

\section{Cognitive impairment}

In the present study, the prevalence of cognitive impairment among the elderly was $13.04 \%$ only. This finding was consistent with a study done by Khaw, Teo, and Rashid in Malaysia, who observed $12.3 \%$ of cognitive impairment. Ortiz et al., reported $13.8 \%$ in Mexico and Giri et al., observed $12.6 \%$ of cognitive impairment in Chongqing China. A study by Sidik et al. in Malaysia and Bista and Joshi in Nepal showed higher prevalance of cognitive impairment, which were $22.4 \%$ and $67 \%$ respectively. Sharifah Zainiyah et al., observed $4.0 \%$ cognitive impairment in Malaysian Day Care Centre and Sharma, Mazta and Parashar, observed $4 \%$ and $3.5 \%$ of cognitive impairment respectively in India.

\section{Associations between cognitive impairment and socio- demographic factors}

In this study, the prevalence of cognitive impairment was highest among respondents aged more than 80 years and the finding was statistically significant. A similar finding was noted in various other studies. Jorm and Jolley, revealed that the incidence of cognitive impairment rises sharply with the age of 90 years where the cognitive impairment doubles every 5.2 years. The age-related changes in cognition are not uniform across all cognitive domains or all older individuals. The basic cognitive functions most affected by age are attention and memory and in the present study, the most affected domain was memory recall (50\%).

Respondents who had no education showed the highest prevalence of cognitive impairment compared to the respondents with some education and similar findings were noted by Sidik et. al., Sharma, Mazta, and Parashar, Giri et al., and Bista and Joshi. This may

Table 2: Distribution of Barthel index of activities of daily living.

\begin{tabular}{|c|c|c|}
\hline S. no & Activities of Daily Living & Prevalence of functional Dependence (\%) \\
\hline & Bowel control-incontinence or occasional incontinence & $11(23.91)$ \\
\hline & Bladder control-incontinence or occasional incontinence & $14(30.43)$ \\
\hline & Grooming-unable or needs help & $3(6.5)$ \\
\hline & Using the Toilet-unable or needs help & $9(19.56)$ \\
\hline & Feeding-unable or needs help & $4(8.69)$ \\
\hline & Transfer to bed-unable or needs help & $26(56.52)$ \\
\hline & Mobility on level surfaces-immobile, or using a wheelchair, or needs help & $24(54.54)$ \\
\hline & Dressing-unable or needs help & $13(28.26)$ \\
\hline & Climbing Stairs - unable or needs help & $32(69.56)$ \\
\hline & Bathing - unable or needs help & $6(13.04)$ \\
\hline
\end{tabular}


Table 3: Associations between socio demographic variables and cognitive impairment of the respondents.

\begin{tabular}{|c|c|c|c|c|c|}
\hline \multirow{2}{*}{\multicolumn{2}{|c|}{ Socio demographic variables }} & \multicolumn{4}{|c|}{ Cognitive Impairment } \\
\hline & & \multirow{2}{*}{$\begin{array}{c}\text { Normal }(n=40) \\
12(92.31 \%)\end{array}$} & \multirow{2}{*}{$\begin{array}{c}\text { Impairment }(\mathbf{n}=6) \\
1(7.69 \%)\end{array}$} & \multirow{2}{*}{$\begin{array}{c}\text { Total (N) }(\%) \\
13\end{array}$} & \multirow{2}{*}{$\begin{array}{l}\text { P value } \\
0.479^{\text {ns }}\end{array}$} \\
\hline & $60-69$ & & & & \\
\hline Age & $70-79$ & $17(100 \%)$ & 0 & 17 & $0.051^{\text {ns }}$ \\
\hline & $80-89$ & $11(68.75 \%)$ & $5(31.25 \%)$ & 16 & $0.015 \mathrm{~s}$ \\
\hline \multirow{2}{*}{ Gender } & Female & $20(83.33 \%)$ & $4(16.67 \%)$ & 24 & $0.376^{\text {ns }}$ \\
\hline & Male & $20(90.91 \%)$ & $2(9.09 \%)$ & 22 & $0.376^{\mathrm{ns}}$ \\
\hline \multirow{3}{*}{ Religion } & Muslim & $26(81.25 \%)$ & $6(18.75 \%)$ & 32 & $0.097^{\text {ns }}$ \\
\hline & Hindu & $9(100 \%)$ & 0 & 9 & $0.248^{\text {ns }}$ \\
\hline & Christian & $5(100 \%)$ & 0 & 5 & $0.480^{\text {ns }}$ \\
\hline \multirow{2}{*}{ Past working status } & No work & $13(86.66 \%)$ & $2(13.34 \%)$ & 15 & $0.649^{\text {ns }}$ \\
\hline & Used to work & $27(87.1 \%)$ & $4(12.90 \%)$ & 31 & $0.649^{\text {ns }}$ \\
\hline \multirow{2}{*}{ Marital status } & Ever married & $36(87.81 \%)$ & $5(12.19 \%)$ & 41 & $0.520^{\text {ns }}$ \\
\hline & Never married & $4(80 \%)$ & $1(20 \%)$ & 5 & $0.520^{\text {ns }}$ \\
\hline \multirow{2}{*}{ Education status } & No education & $9(81.82 \%)$ & $2(18.18 \%)$ & 11 & $0.445^{\text {ns }}$ \\
\hline & Have education & $31(88.58 \%)$ & $4(11.42 \%)$ & 35 & $0.445^{\text {ns }}$ \\
\hline \multirow{2}{*}{ Parity } & No child & $5(83.33 \%)$ & $1(16.67 \%)$ & 6 & $0.590^{\text {ns }}$ \\
\hline & 1 or more children & $35(87.5 \%)$ & $5(12.5 \%)$ & 40 & $0.590^{\text {ns }}$ \\
\hline \multirow{2}{*}{$\begin{array}{l}\text { Consumption of } \\
\text { tobacco }\end{array}$} & Consumed tobacco & $10(90.91 \%)$ & $1(9.09 \%)$ & 11 & $0.555^{\text {ns }}$ \\
\hline & Never consumed & $30(85.72 \%)$ & $5(14.28 \%)$ & 35 & $0.555^{\mathrm{ns}}$ \\
\hline
\end{tabular}

Note: $s=$ Significant, $n s=N o t$ Significant, $P$-value reached from chi square test

be related to increased cognitive reserve with increasing level of education and the bigger the reserve the more protection there is from cognitive impairment. There is also some evidence that mental stimulation can delay the onset of cognitive impairment. On the contrary, Sharifah Zainiyah et al., and Zhuang et al., noted a higher prevalence of cognitive impairment in respondents with higher education.

In this study, the prevalence of cognitive impairment was higher among respondents who were single and similar findings were noted by Sidik et. al and Rashid, Azizah and Rohana. Marriage has protective benefits on cognitive function and the engagement of married individuals in social and cognitive activities are likely to be higher than single individuals and can protect them from cognitive impairment [19].

The unemployed respondents had a higher prevalence of cognitive impairment and similar findings were noted by Sidik et., al; Khaw, Teo, and Rashid, Azizah and Rohana, and Ortiz et al. Studies have suggested that physical activity, mentally demanding work and higher managerial positions have a positive cognitive influence in later life. [20]. But not all types of occupations have a protective effect against cognitive impairment. Studies conducted in France and Taiwan found that people in lower rank occupations shave a higher risk of cognitive impairment. Possible explanations for the association of occupation and cognitive impairment could be due to the high exposure to toxic exposures, the levels of psychosocial stress in different occupations and the level of mental stimulation required in the job. Also, this study showed a higher prevalence of cognitive impairment among the respondents who had one or more children and the finding is comparable with that of Zhuang et al. Contrary to expectation the respondents who never consumed tobacco had a higher prevalence of cognitive impairment.

\section{Limitations of the study}

The study sample size was small. The study was done in the Aged Care Center, which may reflect the condition of the aged population in the community. Besides social and demographic factors, other factors that are associated with physical disability, depression and cognitive impairment were not considered. The study was done at the bivariate level. Therefore, the net effect of a social-demographic variable (independent variable) on any one of old age, impairment be it physical, cognitive and depression (dependent variable) is not examined by taking into account the impact of other social-demographic variables.

\section{CONCLUSION}

Old age is the time associated with physical, psychological and social changes that lead to vulnerable conditions to acquire physical, psychological and social health problems. The findings of this study showed that the elderly population is vulnerable to physical disability, depression and cognitive impairment and it is found that old age was the significant independent risk factor for physical disability, depression and cognitive impairment. The prevalence of physical disability was found higher among females whereas no difference in the prevalence of physical disability was noticed among other social and demographic factors. The prevalence of depression and cognitive impairment were higher among female respondents and those who were unmarried, illiterate and unemployed.

\section{RECOMMENDATIONS}

A systematic screening program establishing early diagnosis facilities, making general people aware of the rising health problems among the elderly and a community-based study, based on the scientifically selected sample should be conducted, exploring the relationship of 
all possible factors affecting the physical and psychological problem of elderly is important.

\section{REFERENCES}

1. Archana B, Sarala J. Lived experiences of health problems of elderly residing in urban areas, Kathmandu: A pilot study. IJMRHS. 2015;4(4):789.

2. https://www.un.org/en/development/desa/population/ publications/pdf/policy/WPP2015/WPP2015_Highlights.pdf

3. Guilbert JJ. The World Health Report 2006: Working together for health. Educ Health (Abingdon). 2006;19(3):385-387.

4. Powell J, Khan H. Ageing in post-industrial society: Trends and trajectories. J Globalization Stud. 2014;5(2):43-51.

5. Hafez G, Bagchi K, Mahaini R. Caring for the elderly: A report on the status of care for the elderly in the Eastern Mediterranean Region. East Mediterr Health J. 2000;6(4):636-664.

6. Kabir R, Khan H, Kabir M, Rahman M. Population ageing in Bangladesh and its implication on health care. European J Sci Res. 2013;9(3):34-47.

7. Sherina M, Jefferelli S, Noo-Zurani M, Noorlia Y. Prevalence of depression among elderly patients attending a primary health care clinic. Malaysian J Psychiatry. 2002;10(2):23-27.

8. Alshalat ME. Urinary tract infection in home care patients Qatar, Doha. Age and Ageing. 2014;11(3):34-44.

9. Dolai M, Chakrabarty F. Functional status of the elderly santal people. Int J Hum and Soc Sci Inven. 2013;2(1):1-6.

10. Abdul-Manaf MR, Mustafa M, Abdul-Rahman MR, Yusof KH, AbdAziz NA. Factors influencing the prevalence of mental health problems among Malay elderly residing in a rural community: A cross-sectional study. PLos ONE. 2016;11(6):0156937.
11. Lokare P, Karanjekar V, Deotale M, Jawarkar A. Assessment of quality of life among elderly population residing at old age homes. Int J Current Res. 2015;7(4):14552-14555.

12. Sundru M, Goru K. Epidemiological study of depression among population above 60 years in Visakhapatnam, India. Int J Med Sci Public Health. 2013;2(3):695-702.

13. Patil SD, Udayar SE, Shannawaz M. A study of depression level among elderly people in the rural area of Bijapur, India. JCMDS. 2015;4(30):5154-5160.

14. Myers T. Mosby's medical dictionary. 8th edn. St. Louis (Missouri): Mosby, Elsevier, USA. 2009.

15. Ferdous T, Cederholm T, Kabir ZN, Hamadani JD, Wahlin A. Nutritional status and cognitive function in community-living rural Bangladeshi older adults: Data from the poverty and health in ageing project. J Am Geriatr Soc. 2010; 58(5):919-924.

16. Ferri CP, Prince M, Brayne C, Brodaty H, Fratiglioni L, Ganguli M, et al. Global prevalence of dementia: A Delphi consensus study. The Lancet. 2005;366(9503):2112-2117.

17. Mehta C, Desale A, Kakrani V, Bhawalkar J. Economic dependency and depression in elderly. J Krishna Inst Med Sci Uni. 2016;5(1),100-109.

18. Bangladesh Bureau of Statistics. Elderly population in Bangladesh: Current features and future perspectives. 4th ed. Statistics and Informatics Division (SID), Ministry of planning. 2015; 22-43.

19. Giri M, Chen T, Yu W, Lu Y. Prevalence and correlates of cognitive impairment and depression among elderly people in the world's fastest growing city, Chongqing, People's Republic of China. Clin Interv Aging. 2016;11:1091-1098.

20. Khaw C, Teo C, Rashid A. Cognitive impairment and depression among residents of an elderly care home in Penang, Malaysia. The Int J Psychiatry. 2009;1(1):1-9. 